\title{
Monitoring of the 2011 spring low ozone events in the Arctic region
}

\author{
LIU NianQing ${ }^{1,2}$, HUANG FuXiang ${ }^{1,2^{*}} \&$ WANG WeiHe ${ }^{1,2}$ \\ ${ }^{1}$ National Satellite Meteorological Center, Beijing 100081, China; \\ ${ }^{2}$ Key Laboratory of Radiometric Calibration and Validation for Environmental Satellites, China Meteorological Administration, Beijing 100081, \\ China
}

Received May 9, 2011; accepted June 20, 2011

Data from FY-3B SBUS and NOAA SBUV/2 were used to monitor ozone levels in the Arctic region from March 1 to April 5, 2011. Results revealed a significant ozone depletion in the area, with total ozone levels between 200-250 DU. The ozone levels recorded were 100-200 DU below normal, and in some parts the levels were as low as 200 DU, indicating a mini ozone-hole. During the sampling period, the ozone depletion area underwent identifiable expansion and detraction, a rotation around the North Pole from the west to the east, and a longitudinal movement from the Pole, spreading to the mid latitudes. The effects of these rare low ozone events were not only felt in the Arctic, but also extended to densely populated areas between Europe and the middle of Russia. In this region, rapidly increasing levels of ultraviolet radiation were detected at the Earth's surface. Given the significant risk that this poses to both the environment and people's health, this occurrence has significant global implications.

arctic, low ozone events, FY-3 satellite, solar backscatter ultraviolet sounder, vertical ozone profile

Citation: $\quad$ Liu N Q, Huang F X, Wang W H. Monitoring of the 2011 spring low ozone events in the Arctic region. Chinese Sci Bull, 2011, 56: 2893-2896, doi: $10.1007 / \mathrm{s} 11434-011-4636-3$

The depletion of ozone in our atmosphere, especially in the stratosphere, and the resultant effect that this has on the environment, has been a topic of much concern for both atmospheric science and climate change research [1-5]. The discovery of the ozone hole above the South Pole in 1985 provided the first clear evidence that human impacts affect the atmosphere, and was a major catalyst for new research regarding ozone depletion [6]. However, the ozone depletion phenomenon is not unique to the South Polar region, and has occurred at different times and in different places throughout the northern hemisphere [2]. Since 1995, Chinese scientists have continued to monitor the existence of mini-ozone holes over the Tibetan Plateau during the Summer and Winter periods, and have conducted systematic research into the resultant effects of these findings, including seasonal changes and changes in the scope of ozone distributions [7-10]. Furthermore, European scientists also have made discoveries of ozone depletions, as these phenomena occurred throughout Europe [11-16].

*Corresponding author (email: huangfx@cma.gov.cn)
The Chinese new generation polar orbit satellite, FY-3, carrying the SBUS (Solar Backscatter Ultraviolet Sounder), is China's first global ozone-monitoring instrument. The design and channels of the device are similar to those of the American NOAA SBUV/2 (Solar Backscatter Ultraviolet). Both instruments have the capability of monitoring global total ozone, as well as vertical ozone profiles [17,18]. In November 2010, the FY-3B SBUS was launched and began its in-orbit test. The precision of the vertical profile data obtained with the FY-3B SBUS marked significant improvements over its predecessor, and is on par with those of NOAA SBUV/2. The FY-3B SBUS is now regularly used for the ozone monitoring program in China. Prior to the introduction of the FY-3B, the FY-3A carrying the TOU (Total Ozone Unit) also delivered reliable and precise ozone measurement data $[19,20]$. The main difference between the SBUS and TOU lies in the design of channels and observation methods. The SBUS has 12 channels aimed at the surface of the Earth with fixed nadir observation, which provides vertical ozone profile data from the surface to the top of the atmosphere with a spatial resolution of approximately 
$200 \mathrm{~km}[17,18]$. The TOU, on the other hand, uses 6 channels and a scanning method of observation to obtain global total ozone data with a spatial resolution of $50 \mathrm{~km}[19,20]$. With both the SBUS and TOU on board, the FY-3 is able to take full advantage of two different technical monitoring methods which deliver complete and accurate data relating to both total ozone and vertical distribution levels.

In the spring of 2011, the northern polar region experienced the most significant depletion in ozone levels in recorded history. This occurrence was reported by the WMO (World Meteorological Organization, http://www.wmo.int/ pages/mediacentre/press_releases/pr_912_en.html) and Science (http://www.sciencedaily.com/releases/2011/04110405102202. html). In this paper, we present the ozone depletion

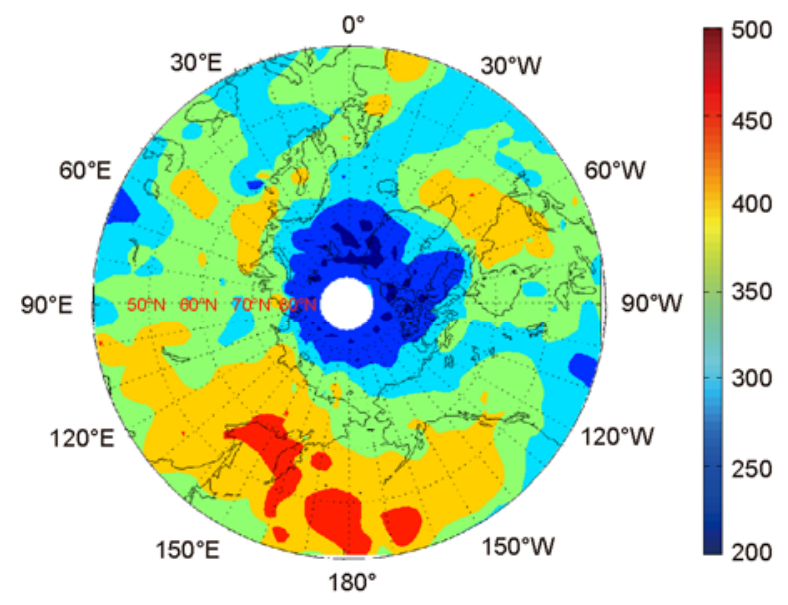

(a) monitoring results using data from the FY-3B SBUS and NOAA SBUV/2s in the Arctic region between March-April, 2011.

The two ozone stereographic polar projection maps in Figure 1 provide a comparison of data obtained from (a) the FY-3B SBUS and NOAA-16, 17, 18 and 19 SBUV/2, with data obtained from (b) the FY-3A TOU over the Arctic region.

Figure 2 shows the total ozone distribution map using data from the WOUDC (World Ozone Ultraviolet Radiation Data Centre) over the Arctic region on March 14, 2011. (http://www.theozonehole.com/arctic2001loss.htm). To allow for comparisons, we have revolved the original map to correspond with the longitudinal position in Figure 1.

Comparing Figures 1 and 2, we can see a clear con

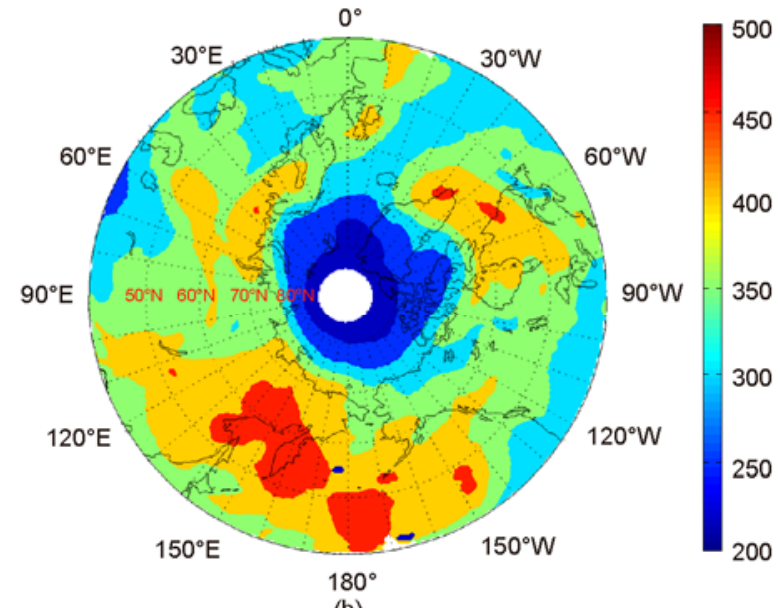

(b)

Figure 1 Comparison of the total ozone stereographic polar projections over the Arctic on March 14, 2011 (DU) from data obtained using (a) the FY-3B SBUS and NOAA SBUV/2s, and (b) the FY-3A TOU.

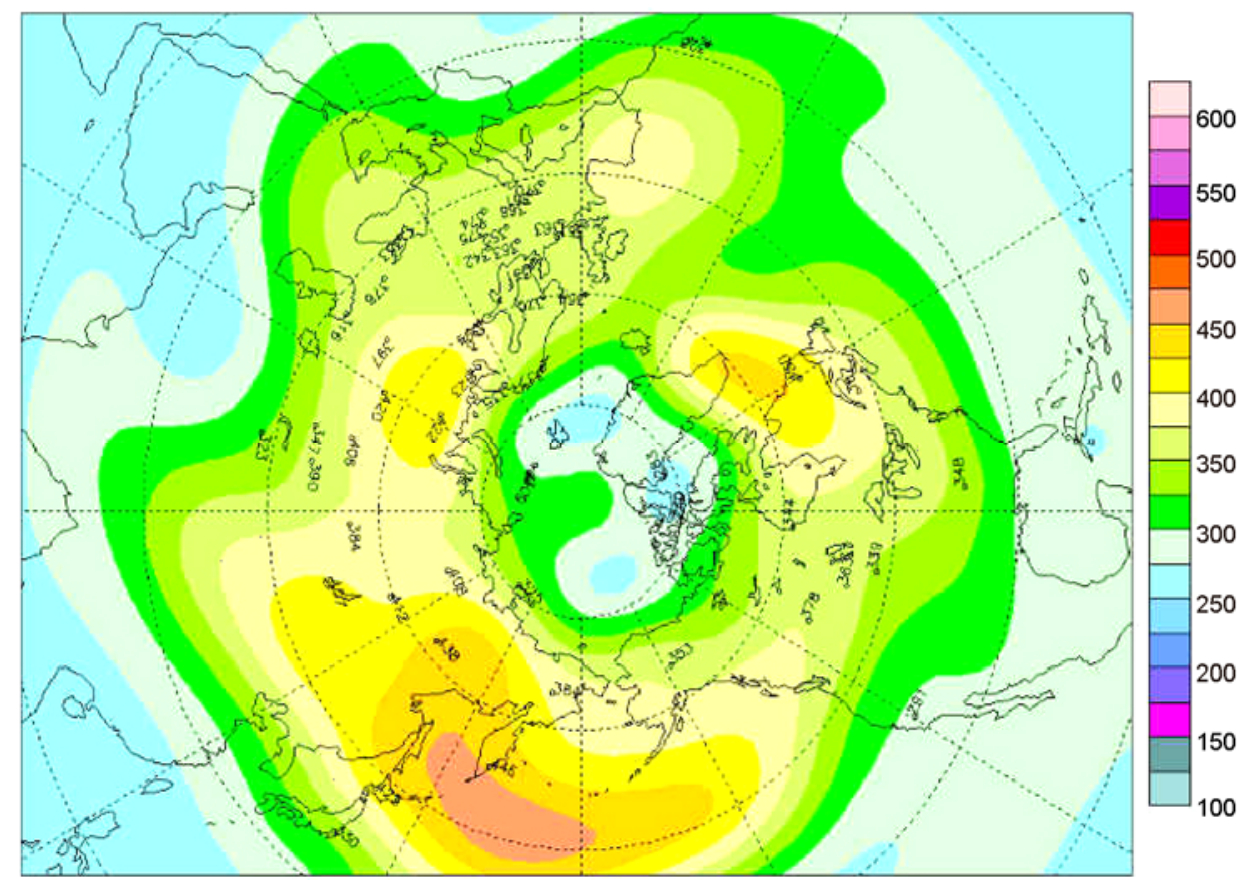

Figure 2 WOUDC Arctic total ozone distribution map for March 14, 2011 (DU). 
sistency between the data obtained from the satellite monitoring and figures obtained from ground observations made by WOUDC. Thus, the similarities between these two sets of figures provides evidence of the reliability and accuracy of the data obtained from the FY-3B SBUS and NOAA SBUV/2.

Figures 1 and 2 both reveal that a sharp reduction in ozone levels revolving around the Arctic Circle occurred on March 14, 2011, in the area north of the $72^{\circ}$ latitude. In this region, total ozone levels were between 200-250 DU, with sections as low as 200 DU, indicating a mini-ozone hole. Since satellite monitoring of ozone levels began in the 1970 s, both vertical ozone profile data and total ozone data revealed that the area around the North Pole normally experiences ozone levels between 300 and 400 DU [21-23]. Thus, it can be said that this phenomenon is the first recorded instance of ozone reduction in the Arctic region.

Figure 3 provides a comparison of vertical ozone profile data taken from the point $71.11^{\circ} \mathrm{N}, 77.09^{\circ} \mathrm{E}$ on March 14 , 2011, with the data taken from same point on March 1, 2011 and April 8, 2011.

As Figure 3 reveals, total ozone levels during ozone reduction periods on March 1, March 14 and April 8, 2011 were 396, 277 and 528.3 DU, respectively. Thus, it is clear from the vertical ozone profile that on March 14, 2011, the area experienced a significant reduction in ozone levels.

From Figure 3, we can further ascertain that the vertical ozone profile data obtained on March 14 show changes in ozone levels mainly in levels 5-10, with a height of around 100-10 hPa. These values correspond to changes from the upper troposphere to the stratosphere. Analyses also revealed that during the period of ozone reduction, ozone levels from the upper troposphere to the stratosphere were approximately 100 DU lower than normal, or 193 DU lower than average high levels. This change represents a change in ozone levels between $77 \%$ and $83 \%$. The data also revealed that the bulk of the changes to ozone levels during this phenomenon occurred mainly between the upper troposphere

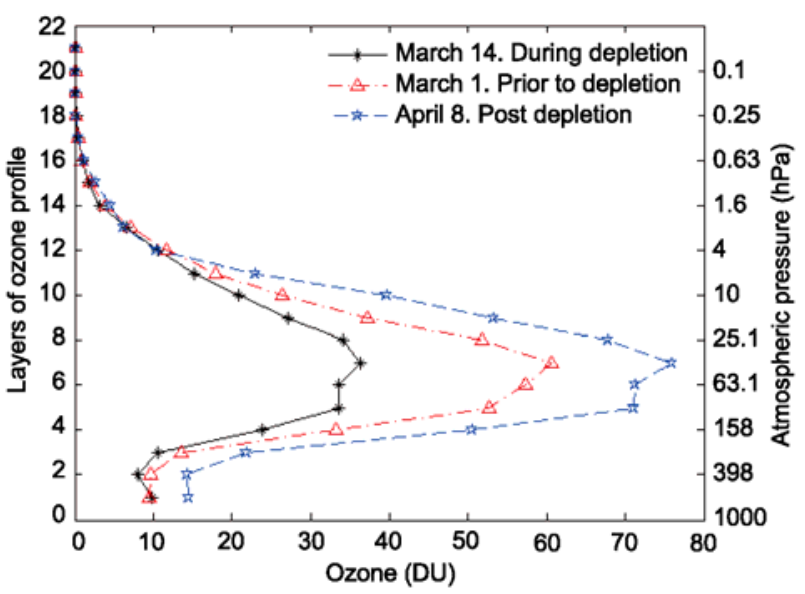

Figure 3 A comparison of vertical ozone profile data obtained on March 1, March 14 and April 8, 2011 at $71.11^{\circ} \mathrm{N}, 77.09^{\circ} \mathrm{E}$. and the stratosphere.

Using data from the FY-3B SBUS and NOAA SBUV/2 constant monitoring from March to April, 2011, we can see the general trend of the ozone depletion in the Arctic region. This instance of depletion in the Arctic region began on March 1, 2011, when ozone distribution levels began to fall (between March 1 and 3) at a relatively fixed area of $80^{\circ} \mathrm{N}$, $90^{\circ} \mathrm{E}$ and $90^{\circ} \mathrm{W}$. From March 4 , the area of reduction began expanding and revolving around the Pole from west to east. On the 10th, the region of reduction began to spread, heading $90^{\circ} \mathrm{W}$ and $40^{\circ} \mathrm{N}$, where it soon developed into a significantly large region of ozone depletion. From March 11-13, the area began expanding from the Pole to $40^{\circ} \mathrm{N}$, and began revolving from west to east, reaching $30^{\circ}-50^{\circ} \mathrm{W}$ on the 13 th. On the 14th, the area began retracting to the Pole, but extended along $70^{\circ} \mathrm{N}$, towards the area around $30^{\circ}-50^{\circ} \mathrm{W}$. On the 15 th, the affected area was focused by the Pole, before developing and stretching along a longitudinal path, and following the Pole's slow rotation from west to east. On the $22 \mathrm{nd}$, the area of ozone reduction appeared at $54^{\circ} \mathrm{N}$ and $120^{\circ} \mathrm{E}$, and headed north where it crossed the North Pole and reached $60^{\circ} \mathrm{N}$ and $60^{\circ} \mathrm{W}$ in a narrow strip-like manner, with the width extending to the $20^{\circ}$ longitude line.

From the 23-25th, the "arm" of the hole appeared spinning anti-clockwise from west to east, and gradually began to break up into parts. From the 25th, the region began extending from the Pole along a longitudinal path until it covered an area with bearings of approximately $45^{\circ} \mathrm{N}, 10^{\circ} \mathrm{W}$ to $25^{\circ} \mathrm{W}$. From March 26 to April 4, the main section of the depletion area covered a region with bearings of approximately $50^{\circ} \mathrm{N}, 10^{\circ} \mathrm{W}$ to $75^{\circ} \mathrm{E}$ and, with the Pole at the centre, slowly began rotating from west to east. From March 26, the size of the area began expanding, and reached its largest size on the 28th, before slowly shrinking in area to its smallest size on April 5. The depletion area then gradually began to leave the Polar region, and small sections could be seen moving towards the equator, signaling the end of this occurrence of ozone reduction.

Figure 4 outlines the size of the area of ozone reduction at its peak during March 28-31, as the region extended to Europe and the middle of Russia. Figure 4(a)-(d) shows the growth of the area during March 28, 29, 30 and 31, respectively.

As Figure 4 reveals, during the period of March 28-31 the area of ozone reduction extended from the Pole and covered a significant area, including western Europe and central Russia. Total ozone levels for the area were between 230-250 DU, with the sections falling below $220 \mathrm{DU}$ reaching the level of a mini-ozone hole.

This occurrence of ozone depletion over the Arctic region lasted over a month, from March 1 to April 5, 2011. Furthermore, the scope and scale of the area, which covered almost all of Europe and the western parts of Asia, posed a threat to not only the health and safety of the people in this region, but also to the environment. The initial observation 


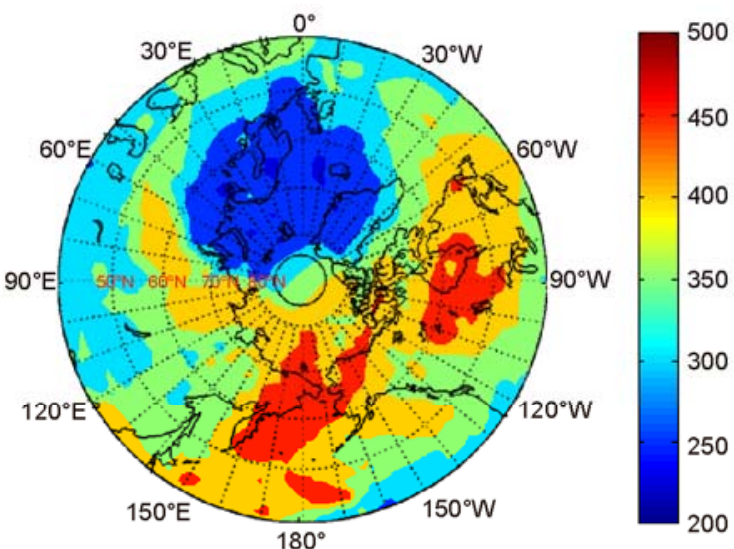

(a)

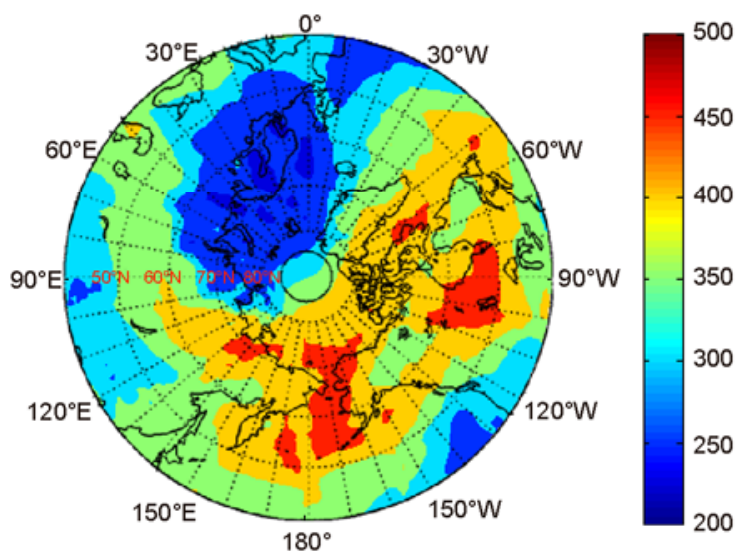

(c)

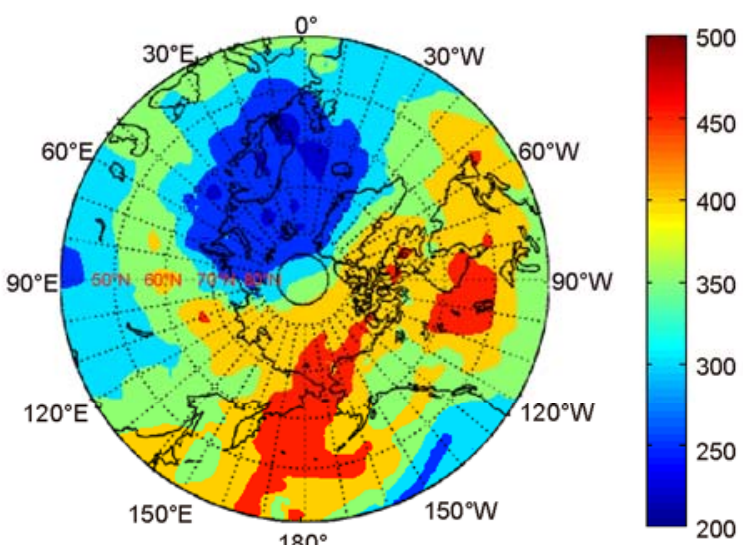

(b)

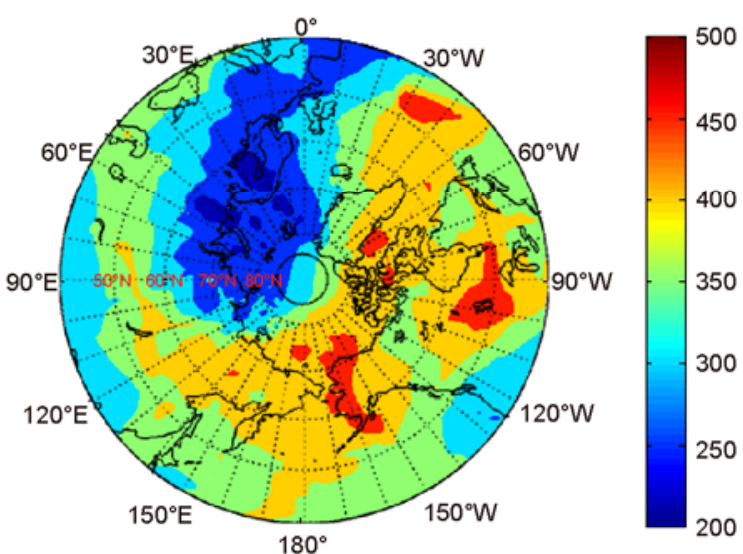

(d)

Figure 4 Movement of the area of ozone reduction heading towards the equator during March 28-31, 2011 (DU).

of the hole in the ozone layer in the south pole in 1985 resulted in long-term monitoring of the situation throughout the Southern Hemisphere. Similarly, the scale and length of the reduction in ozone levels at the north pole, recently witnessed in spring 2011, will undoubtedly attract significant attention from the global community, especially from countries at risk in the Northern Hemisphere.

This work was supported by the National Natural Science Foundation of China (40975016) and the National High-Tech Research \& Development Program of China (2008AA121703).

1 WMO/UNEP. World Meteorological Organization Global Ozone Research and Monitoring Project Report No. 144, 1998

2 WMO/UNEP. The Scientific Assessment Panel of the Montreal Protocol on Substances that Deplete the Ozone Layer Report, 2002

3 WMO/UNEP. The Scientific Assessment Panel of the Montreal Protocol on Substances that deplete the ozone Layer Report, 2006

4 WMO/UNEP. Executive Summary, the Scientific Assessment Panel of the Montreal Protocol on Substances that Deplete the Ozone Layer Report, 2010

5 Bojkov R D, Fioletov V F. J Geophys Res, 1995, 100: 16537-16551

6 Farman J C, Gardiner B J, Shankin M R. Nature, 1985, 315: 207-210

7 Zhou X J, Luo C, Li W L, et al. Chinese Sci Bull, 1995, 40:
1396-1398

8 Zou H. Geophys Res Lett, 1996, 23: 1029-1032

9 Bian J C, Wang G C, Chen H B, et al. Chinese Sci Bull, 2006, 51: 606-609

10 Bian J C. Adv Atmos Sci, 2009, 26: 305-311

11 Janusz, W K. Int J Climatol, 2002, 22: 1425-1439

12 Marc A, Pieter V, Ronald V D, et al. Geophys Res Lett, 2000, 27 : 4089-4092

13 Anoop S M, Marvin S, Hilke O, et al. J Geophys Res, 2010, 115: D20303, doi: 10.1029/2009JD013665

14 McCormack J P, Hood L L. Geophys Res Lett, 1997, 24: 2647-2650

15 Bojkov R D, Balis D S. Annal Geophys, 2001, 19: 797-807

16 Orsolini Y J, Limpasuvan V. Geophys Res Lett, 2001, 20: 4099-4102

17 Huang F X, Liu N Q, Zhao M X, et al. Chinese Sci Bull, 2010, 55: 943-948

18 Huang F X, Liu N Q, Zhang P, et al. Opt Precision Eng, 2010, 18: 1568-1576

19 Wang W H, Zhang X Y, An X Q, et al. Chinese Sci Bull, 2010, 55: 3037-3043

20 Wang Y M, Wang Y J, Wang W H, et al. Chinese Sci Bull, 2010, 55: 84-89

21 Goddard Space Flight Center/NASA. Version 8 TOMS V1-data, V2images, NASA Report, 2004

22 NOAA/NASA Ozone Processing Team. SBUV Version 8 data, NASA Report, 2004

23 Flynn L E, McNamara D, Beck C T, et al. Int J Remot Sens, 2009, 30: 4259-4272

Open Access This article is distributed under the terms of the Creative Commons Attribution License which permits any use, distribution, and reproduction in any medium, provided the original author(s) and source are credited. 